\title{
UMA GALIZA, DOIS OLHARES: FRÍA HORTÊNSIA COMO CONTÍNUO EXERCÍCIO DA MEMÓRIA E DE RESSIGNIFICAÇÃO DO PASSADO MÍTICO GALEGO
}

\author{
Angélica Maria SANTANA BATISTA ${ }^{3}$ \\ Vivian LACERDA MARREIRO ${ }^{4}$
}

A narrativa "Fría Hortênsia" se estrutura de forma que haja duas histórias encaixadas como dois narradores de características diferentes. O primeiro narrador é um adolescente imerso na contemporaneidade, apaixonado por sua prima Maribel e completamente devotado aos seus encontros e desencontros amorosos. Já a segunda narradora é Fría Hortênsia, uma velha campesina cuja notoriedade era a de conhecer várias lendas e mitos autócnes e os transmitia perto de seu caldeirão em sua cozinha dia após dia. O primeiro narrador relata a sua vivência em suas férias de verão no campo e dá voz a Fría quando esta conta uma das cinco invasões de Nosa Terra. Para Flavio García:

O eu da história-moldura, narrador autodiegético, permuta sua função com Fría Hortensia, narrador heterodiegético da históriaemoldurada. Nos momentos em que Fría assume a narração, aquele primeiro narrador, ao lado da prima e dos amigos, assume a função de narratário intratextual. Assim, o movimento eu $\rightarrow$ Fría $\rightarrow$ eu é cíclico e circular na narrativa, constituindo um diálogo entre os dois planos do narrado

Méndez Ferrín faz de sua narrativa primeira - "Fría Hortênsia" - um texto-moldura para uma segunda narrativa - o texto da tradição mítico-celta. O diálogo entre os dois planos da ação, entre as duas enunciações - uma do narrador autodiegético e outra de Fría - promove o surgimento de um terceiro texto, produto do diálogo entre as duas narrações: o texto de uma nova visão histórica. (García: 2004, p. 34)

Ambas as narrativas desenvolvem-se descontinuamente, com retrospectivas, cortes e rupturas do tempo e do espaço, isso se dá com as constantes digressões do primeiro narrador e das contínuas histórias narradas por Fría. O tempo narrado se coloca

\footnotetext{
*Mestranda UERJ

**1 Graduanda UERJ, PIBIC UERJ vinculada ao projeto A presença do insólito na narrativa de ficção: uma questão de gênero, sob orientação do Prof. Dr. Flávio Garcia de Almeida
} 
em um local do passado, o tempo da narração é composto pelas lembranças do adulto que rememora e transmite ao leitor o verão que passara, ainda na adolescência, em Vila Nova dos Infantes, quando mantinha uma paixão platônica pela prima Maribel. O fato de ser autodiegético e altamente comprometido com seus sentimentos do tempo narrado faz com que seja ainda menos confiável que o segundo, Fría Hortensia, que conta a história de um tempo mítico, quando se travaram batalhas entre as imaginárias Nosa Terra e Tagen Ata e, como tal, narra uma história "verdadeira", posto que relembra a origem da terra. Esta mulher é a expressão do narrador que sabe tudo sobre as personagens e tem amplo conhecimento sobre a trama, demonstrando considerável autoridade em relação ao narrado.

O contínuo exercício de memória se desdobra em algumas instâncias interessantes para se evidenciar não só pelas diferentes faces dos narradores, representantes do tempo profano e do plano mítico, da contemporaneidade e da tradição, do literário e da oralidade. Esses desdobramentos são importantes para se pensar na Galiza contemporânea em dois tons: a manifestação de um presente que se coloca como tensão entre a cidade e o campo e o da afirmação da identidade da terra com o resgate dos mitos.

\section{Dois narradores em uma gangorra}

Pensando no conceito de narrador, sabe-se que em uma visão mais superficial, amparada pelo senso comum, enxerga-se o narrador como "que ou aquele que narra, conta, relata" (HOUAISS: 2001). Essa definição simples já aponta para a função do narrador: relatar os fatos que aconteceram ou não com ele.

Em seu famoso artigo "O narrador", Walter Benjamin considera o verdadeiro narrador, o que se assemelha aos sábios, extinto. Para ele, o narrador se coloca como aquele que se entrega a "faculdade de intercambiar experiências (...) a experiência que passa de pessoa a pessoa é a fonte que recorreram todos os narradores" (BENJAMIN: 1994, p. 88) e esse tipo de fenômeno não mais existe, pois a nova narrativa estaria comprometida com a informação, não com seu sentido utilitário, que seria dar conselhos.

O narrador que dá conselhos a partir de sua experiência seria o marinheiro comerciante, que vem de longe para contar suas histórias, ou o camponês sedentário que conhece as histórias e tradições da terra. Ambos se alimentam da tradição oral. Para o 
autor, "a arte de narrar está definhando porque a sabedoria - o lado épico da verdade está definhando" (BENJAMIN: 1994, p.201).

O que interessa no ensaio é que para ele, a narrativa

não está interessada em transmitir o "puro em si" da coisa narrada como uma informação ou um relatório. Ela mergulha a coisa na vida do narrador para em seguida retirá-la dele. Assim se imprime na narrativa a marca do narrador, como a mão de oleiro na argila do vaso (BENJAMIN: 1994, p. 201).

Nesse sentido,

A narração, em seu aspecto sensível, não é de modo algum o produto exclusivo da voz. $\mathrm{Na}$ verdadeira narração, a mão intervém decisivamente, com seus gestos, aprendidos na experiência do trabalho, que sustentam de cem maneiras o fluxo do que é dito (BENJAMIN: 1994, p. 22).

A própria visão do narrador imprime sua marca na história e é esse olhar que atua no ato narrativo. Desse modo, a narração é moldada pelo narrador como o oleiro da metáfora de Benjamin não pela experiência, mas pelo próprio ato de narrar que trabalha com a rememoração dos fatos narrados, posto que tudo aconteceu no passado e é urdido no presente.

Esse tipo de relação existe em Fría Hortênsia, assim descrita: "era alta e fumaba tabaco de picadura. Gastaba reloxo de peto e tocábase cun pano da montaña, que tiraba e recompoñia sobre a testa como os homes fan coas puchas" (FERRÍN: 1982, p. 1) que além de ser a mais velha e, conseqüentemente, mais sábia, conta suas histórias em sua cozinha e o cheiro desta acompanha o narrador de origem mesmo quando a história da invasão cessa e os adolescentes voltam para suas casas na cidade de Ouréns.

É necessário nesse momento pensar na própria estruturação do processo narrativo:

As dominantes que caracterizam o processo narrativo são fundamentalmente três: o processo narrativo funda-se numa atitude de variável distanciamento assumido por um narrador em relação àquilo que narra, assim se instituindo uma alteridade mais ou menos radical entre o sujeito que narra e o objeto do relato, o que favorece a propensão cognitiva difusamente perseguida pela narrativa; o processo narrativo revela uma tendência para a exteriorização, responsável não só pela caracterização e descrição de um universo autônomo 
(personagens, espaços, eventos etc.), mas também pela tentativa não raro assumida pelo narrador de adotar uma atitude neutra perante esse universo; finalmente, o processo narrativo instaura uma dinâmica temporal, imposta desde logo pelo devir cronológico em princípio inerente à história relatada, e em segunda instância perfilhada também pelo discurso, uma vez que o próprio ato de contar não só tenta representar essa temporalidade, como se inscreve, ele próprio, no tempo (LOPES \& REIS: 1988, p.67).

Pensando no processo narrativo, pode-se então dizer que a narrativa se constrói como uma realidade outra em que o narrador se coloca como um demiurgo. A narrativa se autentica pela atuação do narrador consciente de seu poder a ponto de estabelecer diálogo com o narratário - lembrando que o narratário é "uma entidade ficctícia, um 'ser de papel' com existência puramente textual, dependendo diretamente de outro 'ser de papel' (...), o narrador que lhe dirige de forma expressa ou tácita" (LOPES \& REIS: 1988, p.63) e não deve se confundir com o leitor empírico, real.

O fato de Fría Hortênsia conhecer as histórias de Nosa Terra faz com que o seu ato de contar seja uma volta às origens, fazendo com que sua narração se configure em um tempo mítico, atemporal. Essa atemporalidade não se confunde com uma leitura aistórica das lendas, pois para a narradora e seus ouvintes os acontecimentos do passado são reflexo do presente e, quem sabe, do futuro de Nosa Terra, pois a sua história não finalizara.

Fría preserva sua cultura, compreendendo-se esta como a troca de significados e a conservação de símbolos. Segundo Anthony Giddens,

nas sociedades tradicionais, o passado é venerado e os símbolos são valorizados porque contêm e perpetuam a experiência de gerações. A tradição é um meio de lidar com o tempo e o espaço, inserindo qualquer atividade ou experiência particular na continuidade do passado, presente e futuro, os quais, por sua vez, são estruturados por práticas sociais recorrentes (apud HALL: 1999, p. 14)

Nessa perspectiva:

Cantar ou contar histórias à beira do lume, junto aos caldeirões da cozinha, enquanto se catavam os grãos, se amassava o pão, se guardava a comida aprontar (...), é uma tradição galega (...) foi graças a esse costume que a língua e cultura autóctones se preservaram, já que permaneceram séculos alijadas dos espaços oficiais (GARCÍA: 2004, p. 34) 
Pode-se notar, ao longo da narrativa, o quanto se delineiam marcas de uma busca e preservação identitária. Nesse contexto, faz-se primordial pensar o porquê da escolha dessa personagem - mulher simples, de moderada idade - como a detentora da sabedoria popular, transmitida essencialmente através da oralidade:

Seica visitades moito a Fría Hortensia, dixo un día meu pai acendendo o cachimbo lentamente ao tempo que ollaba cara a fiestra como se puidera ver ao través das cortinas. Sorriu como pra si mesmo. Eu tamén ía á súa cociña cando era rapaz, dixo antes de se erguer pra subir moi a modo as esqueiras en procura da sesta con mamai, dos libros, do silencio, do Daiquiri de final de tarde. Nós non dixemos nada, pro realmente Maribel e mais eu pensabamos se el sería certo que Fría Hortensia era tan vella (FERRÍN: 1982, p.95).

A personagem se coloca como contadora de histórias e de transmissora da tradição. $O$ fato de o pai do narrador ter também visitado a idosa demonstra um movimento circular não só nas narrativas como na própria família do adolescente. Outro fator de circularidade são as diferentes histórias que funcionam como anexo da história principal - a invasão de Nosa Terra -, explicando cada pormenor, como o ocorrido na história do Pote de Granel, em que Fría Hortência fica irritada com a interrupção de Maribel:

Maribel, moi impresionada, interrompera entón a Fría Hortensia pra lle preguntar detalles do pote maravilloso. Non sei se queredes saber o que foi de Isebelt na Nosa Terra ou preferides que vos conte o conto dese estúpido caldeiro, dixera Fría pousando as mans, as súas enormes mans, enriba da artesa. Logo limpou os narices con dous dedos, fungando moito, e chimpou a mocada no fregadeiro de pedra. O Lolo, Maribel, o Carrollas e eu ollámonos en silencio e, de contado, seguimos a debullar nos feixóns. Maribel propuxo saber o máis elemental sobre o Pote de Gradel, e, de seguida, que Fría Hortensia nos contase o resto da historia de Isebelt. Deste xeito - protestei eu - cando Fría continúe a historia verdadeira, estaremos coa imaxinación aínda no pote de Gradel e non prestaremos a debida atención. ¡O Pote nunca ensombrece nada! ¡O Pote de Gradel dá luz!, berrara entón Maribel nun súpeto que me meteu medo (FERRÍN: 1982, p. 93).

A presença desse narrador apegado às tradições é um contraste com o primeiro narrador que está presente na modernidade e focado em seus sentimentos por sua prima, não se preocupando, assim, com o destino de Nosa Terra. O encaixe dos dois tempos - 
mítico e profano, como se verá mais adiante - é a fusão de uma terceira história que se funde a partir de dois olhares que, a princípio, poderiam ser antagônicos, mas são a soma de uma possibilidade de se ler a própria Galiza, visto que mesmo que se conte uma das cinco invasões de Nosa Terra, o que se coloca é a redenção desta, "unha historia ainda non escomenzada" (FERRÍN: 1982, p. 96)

No início de seu artigo "O narrador pós-moderno", em uma clara discussão com Benjamin, Silviano Santiago discute o ato de narrar como duas experiências: o narrador transmite uma vivência ou passa uma informação sobre outra pessoa: "No primeiro caso, a narrativa expressa a experiência de uma ação; no outro, é a experiência proporcionada por um olhar lançado" (SANTIAGO: 1989, p. 38). De qualquer forma, “o que está em questão é a noção de autenticidade” (SANTIAGO: 1989, p. 38).

Nesse sentido, a escolha da voz narrativa antes de tudo se presta à autenticidade da trama. Para Silviano Santiago, o narrador pós-moderno olha para informar e não para compor sua experiência, pois

ele é puro ficcionista, pois tem de dar "autenticidade" a uma ação que, por não ter respaldo de vivência, estaria desprovida de autenticidade. Esta advém da verossimilhança que é produto da lógica interna do relato. $\mathrm{O}$ narrador pós-moderno sabe que o "real" e o "autêntico" são construções de linguagem (SANTIAGO: 1989, p. 40).

O narrador e o narrado se mesclam, pois os fatos se colocam a partir do narrador, mesmo que este não participe efetivamente do narrado. O que se exalta é o olhar, não a ação. A ação acaba por ser filtrada pelo olhar:

Se falta à ação representada o respaldo da experiência, esta, por sua vez, passa a ser vinculada ao olhar. A experiência do olhar. O narrador que olha é a contradição e a redenção da palavra na época da imagem. Ele olha para que o seu olhar se recubra de palavra, constituindo uma narrativa (SANTIAGO: 1989, p. 51).

O primeiro narrador é consciente de que o que se dá é a ficção. O tempo dele no campo e o passado da terra contado por Fría não são parte de sua vivência: são histórias inacabadas, como se percebe no fim do conto:

Pro todo isto é materia doutros relatos, acaídos pra seren contados noutro tempo que non é este tempo. Agora ide indo, porque me sinto moi cansa e xa vos relatei a historia. Foi a historia dunha das cinco invasións que sofreu a Nosa Terra. 
Unha historia que, coma todas, é incompleta (FERRÍN: 1982, p. 118)

Mesmo que as palavras venham do segundo narrador, é o narrador de origem que administra a história e, como tal, faz com que tudo se coloque a partir de sua memória, de suas impressões, de seu olhar. Percebe-se que o adolescente não se coloca no mesmo nível de Fría Hortência também pelo fato de ser da cidade e não falar o dialeto, como Carrolas e Xela, cujo conhecimento sobre as histórias de Fría era maior, já que ouviram outras histórias no inverno anterior. A diferenciação entre os adolescentes da cidade e do campo - o narrador e Maribel de um lado e Carrolas e Xela de outro - é desdobramento da diferenciação entre as histórias.

Fría - inquiriu Xela -, ¿e logo a historia do neno que vai nacer será a do rendentor da Nosa Terra, a historia que tantas veces nos anunciaches o inverno pasado? Ollei pra Maribel desconcertado. Durante o inverno pasado nin ela nin eu escoitaramos a Fría Hortensia, nin ela nin eu estiveramos en Vilanova. Maribel sorría cos ollos baixos e abaneaba a testa cun aceno de pacífica negativa. Xela, por favor - dixo Fría Hortensia cun ton no que se mesturaba a reconvención coa paciencia -, cada conto ten a súa malicia (FERRÍN: 1982, p. 96, grifo nosso).

Outro ponto a ser salientado é a solidão o narrador da história-moldura e da impossibilidade deste em alcançar Maribel, cujo relacionamento próximo de Fría Hortência, excluindo-o das histórias e da sabedoria, fazem com que mais uma vez as histórias possam ser vistas como complementares, porém diversas. $\mathrm{O}$ adolescente vê as histórias como simples ficção, coisa velha:

Pensei agremente en Maribel, e a lúa toda posuíume por dentro. Pro, entón, ollei dúas formas inmóbeis ao pé mesmo da torre. Unha delas, sentada nun mazadoiro, tiña a cabeza iridiscente, batuxada de tímidas estrelas. Ollaba cara arriba, cara a figura esguía de Fría Hortensia que debuxaba un signo con ambos brazos despregados. Maribel ollaba unha estatua lourida que era Fría Hortensia e que, baixo o poder do plenilunio, algunha cousa impensábel lle dicía sen verbas. ¡Horríbel presencia de Maribel lonxe de min, a recibir de Fría Hortensia sabe o diaño que estrépitos de cousa morta e de sabedoría rota! Os tellados de Vilanova, vistos desde o patín do castelo, eran agora azulados e vaporosos. Senteime no chan, agachado nas sombras da porta, e chorei porque me sentía só e aloumiñado polas mans aluaradas da Nosa Terra. Maribel non quixera pasear comigo en tándem 
naquela noite que endexamais esquecerei (FERRÍN: 1982, p. 98).

A partir desse episódio, é possível ver o olhar comprometido desse narrador: seus sentimentos estão tão confusos no tempo narrado que a narração dos fatos se faz ora em tom revoltoso ora com nostalgia. Essa revolta se inicia no adolescente e permanece no adulto. Contudo, a sensação de liberdade e o contato com a natureza fizeram com que a alegria fosse constante, mesmo que por vezes nublada por causa de sua indefinível prima. Ele mesmo admite que o verão distante que passara com sua prima foi uma espécie de vértice, onde diferentes mundos se confundiram: o seu com o de Maribel, os da cidade com os do campo. Esse verão foi, no entanto, "irrepetível: xá tan distante, tan distante" (FERRÍN: 1982, p. 95)

\section{O Maravilhoso como possibilidade de leitura}

O que salta aos olhos no conto é a retomada de mitos de formação galega e da consciência de que a partir da cozinha de Fría Hortência é possível a presença de um mundo maravilhoso, cujas regras estão além das diferenças relacionadas anteriormente. Essa retomada da tradição mítica acaba por ser uma ressignificação do Maravilhoso, pois:

No Maravilhoso não se verifica sequer a tentativa de fazer passar por reais os acontecimentos insólitos e o mundo mais ou menos alucinado em que eles têm lugar. Estabelece-se, deste modo, como que um pacto tácito entre o narrador e o receptor do enunciado: este deve aceitar todos os fenômenos nele surgidos de forma apriorística, como dados irrecusáveis e, portanto, não passíveis de debate sobre sua natureza e causas. Em contrapartida, a narrativa não procurará levá-lo dolosamente a considerar possível o sobrenatural desregrado que lhe propõe, mostrando-lhe desde cedo que a fenomenologia nela representada não tem nem pretende ter nada de comum com o mundo empírico (FURTADO: 1980, p. 35).

Para Jacques Le Goff:

Uma das características do maravilhoso é o ser produzido, certamente, por forças ou por seres sobrenaturais, que são, precisamente, inumeráveis. E uma marca de tal facto pode ser encontrada, creio eu, no plural mirabilia da Idade Média. A realidade é que não apenas temos um mundo de objectos, um 
mundo de ações diversas, mas que por detrás deles há uma multiplicidade de forças (LE GOFF: 1983, p. 23).

De acordo com Nelly Novaes Coelho, os contos maravilhosos possuem constantes que muitas vezes relembram os ritos iniciáticos como: metamorfose dos heróis por meio do encantamento, o uso de talismãs ou objetos mágicos, a força do destino, o desafio do mistério ou do interdito, a reiteração dos números (principalmente três e sete), intervenção mágica para a resolução dos problemas e fortes valores éticoideológicos (COELHO: 2000). Algumas dessas se encontram na narrativa de Méndez Ferrín.

Tais conceitos podem ser perfeitamente averiguados na análise de "Fría Hortênsia", na qual nota-se, no texto, a materialização por meio da linguagem desse universo insólito próprio do Maravilhoso. Um bom exemplo é dado quando, inicialmente, a narradora apresenta o rei de Tagen Ata, Enmek Tofen, demonstrando em sua descrição um ser dotado de características e/ou poderes sobrenaturais capaz de colocá-lo num patamar de superioridade em relação aos demais personagens, estabelecendo-se, pois uma hierarquização para além de sua autoridade monárquica, transformando-o em um Ente Sobrenatural: "Era máis alto, máis forte e máis fermoso que calquera outro home (...) a voz do rei era tan potente que foi oída, tanto polos seus, como polos estranxeiros que quedar quedarían maravillados ao tempo que botaban as áncoras e arriaban as velas" (FERRÍN: 1982, p. 89-90).

A ambientação em um espaço maravilhoso se dá não só pela construção de uma realidade calcada na sobrenaturalidade como pelo respeito das personagens da históriamoldura pela narração de Fría, a ponto de todas as interferências destas não saírem espaço maravilhoso:

¿Como Isebelt podía falar co estorniño?, preguntou o Lolo nun súpeto. Todos nós, daquela, chantamos a nosa ollada en Fría Hortensia, coma quen respalda a interrupción e fai súa a perplexidade do Lolo. Fría deixou de remexer no pote do caldo, que ficou oscilando, pendurado da gramalleira. Púxose de pé, pegoulle un toque imperceitíbel ao pano da cabeza, apoiou ambos puños nas cadeiras, imprimiulle ao seu corpo un balance case circular. ¿A vós que vos parece?, preguntou con ese ar distante, estúpido e suficiente que, por veces, adoptan os escolantes. Isebelt sabería a linguaxe dos paxaros, aventurou Xela. Ou non - dixo Maribel -, ao mellor aquela fonte era do Outro Mundo e ao seu carón as persoas podían entenderse cos animais. Tamén pode ser que se tratase dun ser humano que, por 
algunha fada, se vira obrigado a levar a apariencia dun estorniño - comentou, sen demasiada convicción, o Carrollas (FERRÍN:1982, p. 99-100).

Todas as explicações dos jovens estão calcadas na sobrenaturalidade: não é possível dentro do universo de Fría Hortência sair dessa realidade os primeiros narratários sabem disso. A gargalhada de Fría diante dessas diferentes versões para o fato sugere o prazer desta diante da confusão de seus ouvintes. O Maravilhoso é naturalizado no decorrer da narrativa, produzindo outro sentido, resultante do contato entre o natural e o sobrenatural. Irlemar Chimpi afirma: "o efeito de encantamento do leitor é provocado pela percepção da contiguidade entre as esferas do real e do irreal, pela revelação de uma causalidade onipresente, por mais velada e difusa que esteja" (2008, p. 61). Essa causalidade onipresente sentida pelos adolescentes é que dá às versões respaldo, visto que dentro do universo representado elas possuem lógica. A verdade, porém, é que "comprendía e falaba as linguaxes de todos os seres, incluíndo as prantas e tamén as pedras, os tarreos, os edificios e os ventos. Só non podia falar as linguaxes dos seres humanos" (FERRÍN: 1982, p. 100)

Dando vez a história narrada por Fría Hortência, após a apresentação de Enmek Tofen, rei de Tagen Ata, apresenta-se o outro rei, Dindadigoe, vindo de Nosa Terra com a pretensão de se casar com Isebelt, irmã de Enmek Tofen, Malabron, Lodr e Kodraf, representantes da realeza de Tagen Ata. Este casamento seria a possibilidade de estabelecerem-se vínculos de amizade entre os dois reinos. A narradora põe em foco Kodraf como o possível anti-herói, diz que ele fora o único a não se encantar com o casamento: "Hai homes que odian ás bolboretas e que só son felices cando ven a discórdia. Son os homes máis malvados.(...) Non te esquezas de que en todas as historias hai un home que ten que facer o mal, todo o mal do mundo" (FERRÍN: 1982, p. 91).

O casamento é estremecido pela atuação de Kodraf, que castra os cavalos dos de Nosa Terra e os mata. Enmek Tofen faz o seguinte acordo com Dindadigoe em troca da paz: "Se ti accedes a esquencer a ofensa recibida, dareiche en compensación dous cabalos por cada un dos que perdeches e mais a miña espada Derbfoll, forxada polos deuses de antanto, que é capaz de cortar o mármore e a pedra” (FERRÍN: 1982, p. 92). $\mathrm{Na}$ festa de casamento, o rei de Tagen Ata pede perdão total e diz: "Dareiche un pote de ouro, chamado Pote de Gradel, no que, se metes a cocer un home morto, sairá del vivo, aínda que mudo e cos ollos louleados" (FERRÍN: 1982, p. 93). 
O casamento se faz, e nasce Em Dovel, que deveria ser aquele que governaria as duas nações. Contudo, o povo de Nosa Terra não esquecera as ofensas de kodraf e Isebelt sofre o castigo pelos atos do irmão, sendo obrigada a

\begin{abstract}
ir vivir a unha chouza situada na porta do pazo do rei; que a súa ocupación habería de ser a de arrincar as víceras dos animais destinados a seren comidos cada día; que, ao acabar a xornada, recibiría unha pancada do carniceiro maior como premio ao seu labor. Finalmente, Isebelt apousaría na porta do pazo, cando non tivera traballo, e transportaría sobre o seu lombo ante Dindadigoe a tódolos visitantes e estranxeiros que aló se achegasen (FERRÍN: 1982, p. 99).
\end{abstract}

A condição de Isebelt em ter sua condição de rainha amputada se assemelha a contos maravilhosos em que as personagens tinham seus direitos extirpados e sofriam também fisicamente alguma provação e recebiam o escárnio das demais personagens. $\mathrm{O}$ fato do estorninho se colocar como elemento mágico auxiliador também é outra marca recorrente no gênero maravilhoso, assim como o fato de a mensagem da irmã sofredora não chegar de forma simples a Enmek Tofen, sendo necessária a atuação do Lobo Vela e da água Cirus.

Quando, mais uma vez, os dois reinos tentam se esquivar de outra batalha, estabelecendo a paz através de En Dovel - filho de Dindadigoe e Isebelt e esperança da unificação entre as duas terras, bem como da manutenção do equilíbrio - Kodraf realiza mais um ato ato de crueldade:

Kodraf pegaba un chouto de pantera, como collía ao meñino polo pescozo e como ele abría o peito dunha coitelada (...) choutaba até o alto do sitial de En Dovel, agarraba a este e tiráballe o corazón pra fora (...) cun berro animal, collía xa a Em Dovel polas perniñas e chimpábao na fogueira (...) como o cazador colle á lebre (FERRÌN: 1982, p. 110).

Deve-se destacar, ainda, que na história de Fría Hortensia não há vencedores. Inicialmente, a tropa de Dindadigoe - rei de Nosa Terra - é favorecida pelo "Pote de Gradel", entretanto, após Isebelt destruí-lo, as condições de batalha se igualam. Por fim, Isebelt morre, Dindadigoe e Enmek Tofen matam-se um ao outro e Lodr mata o irmão Kodraf - causador de toda a discórdia.

A narrativa de Fría Hortensia termina dizendo que Lodr retorna para Tagen Ata com o coração de Enmek Tofen em suas mãos, desejando com todas as suas forças que 
o irmão viva novamente, então, atira seu coração nas águas onde caíra a Espada de Derbfoll:

De xeonllos sobor da ponte do navío, Lodr sostiña o corazón de Enmek Tofen nunha copa de prata. Unha luz cegadora surtía do corazón e ventos estraños gobernaban de seu as velas e o leme. Cantaba o mar unha múltiple cantiga de tristura no courel e na quilla. Cun xesto estricto, Lodr deixa caer o corazón de Enmek Tofen no mar que separa a Nosa Terra de Tagen Ata. O corazón entra nas augas ao tempo que un lóstrengo vivísimo cega os ollos de Lodr. O día escurece, prodúcense tronos espantosos, todo mundo é cuberto por un manto de frio (FERRÍN: 1982, p. 118)

Na sequência, um peixe come o coração do rei de Tagen Ata, esse peixe é comprado por uma mulher chamada María e eis que Enmek Tofen renasce pela boca desta mulher. Fría Hortensia conclui sua exposição afirmando que o rei se tornará novamente o poderoso herói de Tagen Ata, ameaçando assim Nosa Terra: "Pro todo isto é materia doutros relatos, acaídos pra seren contados noutro tempo que non é este tempo" (FERRÍN: 1982, p. 118).

Portanto, conclui-se que as duas realidades - a do tempo profano e a do tempo mítico se alternam e, juntas, compõem um todo, semelhantemente aos diferentes planos narrativos. O Real e o Maravilhoso convivem, sem que um negue o outro. Esta complementariedade também pode ser reforçada pela simbologia do número cinco, recorrente nas obras ferrinianas. Segundo Chevalier e Gheerbrant, o número cinco é símbolo de união, expressa também harmonia e o equilíbrio e ainda é representante da ordem e da perfeição (Cf. CHEVALIER; GHEERBRANT: 1998, p. 241- 242).

Assim, depreende-se que por meio da estratégia de utilizar diferentes planos narrativos em distintos tempos, encaixando suas histórias, rompem-se as dicotomias tempo profano/tempo mítico, contemporaneidade/ tradição, literário/ oralidade, campo/ cidade, e com isso exaltam-se diferentes olhares que compõem uma mesma Galiza. A ambivalência dos narradores e suas díspares realidades se completam, permeadas pela rememoração, seja do narrador original, seja do narrador originário, e inserem a Galiza em um processo de autoconhecimento, de busca de uma identidade própria, completa e perfeita, por muito tempo negada e desvalorizada no cenário europeu.

\section{Referências bibliográficas:}


BENJAMIN, Walter. Magia e técnica, arte e política: ensaios sobre literatura e história da cultura. São Paulo: Brasiliense, 1994.

CHEVALIER, Jean; GHEERBRANT, Alain. Dicionário de símbolos (mitos, sonhos, costumes, gestos, formas, figuras, cores, números) / Jean Chevalier, Alain Gheerbrant, com a colaboração de: André Barbault et al.; coordenação Carlos Sussekind; trad. Vera da Costa e Silva et al.- 12.ed. - R. J.: José Olympio, 1998, p. 2412.

CHIAMPI, Irlemar. O Realismo Maravilhoso:forma e ideologia no romance hispano-americano- 2.ed. S. P.: Perspectiva, 2008.

COELHO, Nelly Novaes. Literaratura Infantil: teoria análise, didática. São Paulo: Moderna, 2000.

FERRÍN, X. L. Méndez. "Fría Hortensia” . In: Amor de Artur 1982.

FURTADO, Filipe. A Construção do Fantástico na Narrativa. Lisboa: Horizonte, 1980.

GARCÍA, Flavio. "Galiza, terra celta: identidade, contos de vella, literatura". In: Sentidos dos lugares. Rio de Janeiro: ABRALIC. Edição em CD Rom. 2005.

Tensões entre questões e conceitos na proposição de um outro e novo gênero literário: o Insólito Banalizado. In: XIV Congresso da ASSEL-III Enletrarte, 2007, Campos. Anais do XIV Congresso da ASSEL-Rio e III ENLETRARTE. Campos: ASSEL-Rio CEFET Campos, 2007.

HALL, Stuart. A identidade cultural na pós-modernidade. Trad. Tomaz Tadeu da Silva e Guacira Lopes Louro- 3.ed. - R. J.: DP\&A, 1999, p.14-5.

HOUAISS. Dicionário eletrônico da língua portuguesa, 2001.

LE GOFF, Jacques. O Maravilhoso e o quotidiano no ocidente medieval. Trad. Antônio José Pinto Ribeiro. Lisboa: Edições 70, 1983, p. 9-35.

LOPES, Ana Cristina M. \& REIS, Carlos. Dicionário da teoria da narrativa. São Paulo: Ática, 1988.

SANTIAGO, Silviano. "O narrador pós-moderno". In: Nas malhas da letra. São Paulo: Cia. das Letras, 1989. 